\title{
The effect of therapeutic exercise and vegan diet on pain and quality of life in young female patients with chronic non-specific neck pain
}

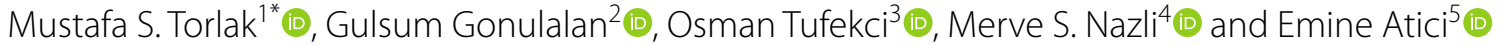

\begin{abstract}
Background and purpose: In recent years, dietary practices have begun to be used in painful conditions. This study aimed to investigate the effect of a vegan diet and therapeutic exercise in patients with chronic non-specific neck pain.

Materials and methods: A total of 45 young female patients with chronic non-specific neck pain, aged 18-25 years, participated in the study. Body mass index and body fat percentage were measured with bioelectrical impedance analysis. Pain severity was assessed using the Visual Analogue Scale, quality of life with the short form-36 scale, kinesiophobia with the Tampa scale of kinesiophobia and neck disability with the Neck Disability Index.

Results: The pain severity reduced in the diet group and exercise group after treatment ( $p=0.001)$. After treatment, Neck Disability Index score decreased in the diet group and exercise group $(p=0.001)$. Tampa scale of kinesiophobia score decreased in the diet group and exercise group $(p=0.001)$. The eight domains of the short form-36 scale score increased in the diet group and exercise group $(p<0.05)$. No difference was found in the body mass index and fat percentage in all groups before and after treatment ( $p^{>} 0.05$ ).
\end{abstract}

Conclusion: A vegan diet and therapeutic exercise are beneficial to patients with chronic non-specific neck pain in terms of pain severity and quality of life.

Keywords: Diet, Exercise, Pain, Vegan

\section{Introduction}

Neck pain is the fourth leading cause of disability [1]. Prevalence is generally higher in women, higher in economically underdeveloped countries and rural areas $[2$, 3]. Neck pain is classified as specific and non-specific [4]. Non-specific neck pain (NSNP) has no clear identifiable source of pain and originates from the facet joints, ligaments, muscles and intervertebral discs [5]. Causes of NSNP spread over a wide area, mainly due to inadequate ergonomics in the workplace (maintaining the neck

\footnotetext{
*Correspondence: mustafa.savas.torlak@karatay.edu.tr

1 Department of Physical Therapy, Vocational School of Health Services, KTO Karatay University, Akabe Sq, Alaadin Kap St, 41, Karatay, Konya, Turkey

Full list of author information is available at the end of the article
}

posture in a non-physiological position for a long time), anxiety and depression. Neck pain lasting for $<6$ weeks is classified as acute, 3 months and less as subacute and $>3$ months as chronic [6].

Generally, patients with neck pain account for approximately $25 \%$ of outpatient physical therapy clinic visits [7]. The most commonly used treatment methods for neck pain in physical therapy are exercise, manual therapy, low level laser therapy, acupuncture, message and electrotherapy agents $[8,9]$. A recent review stated that non-pharmacological treatment approaches have a low level of evidence [8]. Full recovery after treatment is not achieved in most people with neck pain, and $50-85 \%$ report a recurrence after $1-5$ years [10]. Therefore, neck pain incurs huge costs in terms 
of unnecessary treatment fees and work absenteeism. Thus, new treatment methods are necessary.

Exercise approaches play an important role in neck pain treatment and prevention by activating deep muscles and preventing the excessive activity of superficial muscles [11]. A Cochrane review of randomised controlled trials on the effect of exercises on neck pain noted the role of exercise in acute and chronic neck pain treatment and found moderate evidence for the effectiveness of endurance, strengthening and stretching exercises [12].

Dietary practices increase the quality of life of individuals by reducing the risk of developing many diseases such as diabetes, cardiovascular diseases, kidney failure, cancer and mortality and morbidity rates [13-16]. Vegetarianism is a diet that excludes animalderived foods such as meat products, poultry and fish and includes foods such as fruits, vegetables, grains, legumes, nuts, seeds and honey [17]. Varieties of a vegetarian diet are available, in which seafood (pescetarianism), eggs (ovo-vegetarianism), dairy products (Lacto-vegetarianism) and eggs and dairy products (Lacto-ovo-vegetarianism) are freely consumed [18].

Increased inflammatory responses in the peripheral and central nervous systems play a key role in the development of many pathological pain conditions [19]. Studies reported in the literature indicated that large consumption of animal-derived food is associated with chronic pain and inflammation [20, 21]. A general assumption is that people who avoid animal foods experience less pain. People whose diets are primarily plant-based have a significantly lower prevalence of chronic pain or inflammation than those who eat an average American diet [21]. The typically meat-heavy American diet contributes to blood acid levels, which disrupts $\mathrm{pH}$ and causes an inflammatory response [22]. A plant-based diet of fruits, vegetables and whole grains is rich in vitamins and phytochemicals and produces antioxidant responses [23]. In addition, people on a plant-based diet are closer to their target weight than those who consume a typical American diet [24]. Obesity or excess adipose tissue was long known to positively correlate with inflammatory proteins [25]. Moreover, vegan nutrition has a positive effect on the intestinal microbiota [26]. The gut microbiota played a role in acute and chronic pain pathophysiology, as well as in opioid response [27].

Despite the positive effects of a vegan diet on health, no reported study in the literature has examined the effect on chronic NSNP. Thus, this study aimed to investigate the effect of a vegan diet or therapeutic exercises in individuals with chronic NSNP.

\section{Materials and methods Patients}

This randomised controlled study was conducted in a private university hospital in Konya between May 2021 and July 2021. A total of 45 female patients between the ages of 18 and 25 years (mean $20.91 \pm 1.82$ years) diagnosed with chronic NSNP by a specialist doctor participated in the study. Inclusion criteria for the study are as follows: $18-25$ years old, neck pain for at least 3 months and a Visual Analogue Scale (VAS) score of $>5$. Individuals who regularly take painkillers, have undergone neck surgery, have specific or neurological problems in the neck (for example, vertebral fracture, inflammation, infection, etc.), are pregnant, use cortisone or antidepressants, have serious chronic or psychiatric diseases and have received physical therapy in the last 3 months were excluded from the study.

\section{Sample size}

The sample size calculation was done using a G*power analysis software Version 3.0.10 (G*Power, Franz Faul, Universität Kiel, Germany), which was calculated according to the previous study examining the effect of intermittent diet and physical therapy on chronic pain [28]. Pain level was used to estimate the sample size. The analysis indicated that 15 participants for each group were enough to detect a large Cohen's effect ( $d$ $=0.75$ ) with an alpha error probability of 0.05 and a power of $80 \%$.

\section{Randomisation and blinding}

The diagram describing the patient selection process and study flow is shown in Fig. 1. The study was designed as single-blind. All participants completed an evaluation form before and after the treatment by a single observer, who was blinded to the treatment. Three different treatment options for randomisation were created on the computer by the statistician, put into envelopes and numbered from largest to smallest. A total of 45 patients were divided into 3 groups according to the sequential randomisation method. The person applying the treatment opened these envelopes one by one and applied the treatment in the envelope according to the number of participants. As mentioned above, participants were divided into 3 groups as exercise group (EG) $(n=15)$, diet group (DG) $(n=15)$ and control group (CG) $(n=15)$.

\section{Ethical consideration}

The study protocol was approved by the Non-invasive Clinical Research Ethics Committee of the Faculty of Medicine, the University of XX on 06 October 2020. 


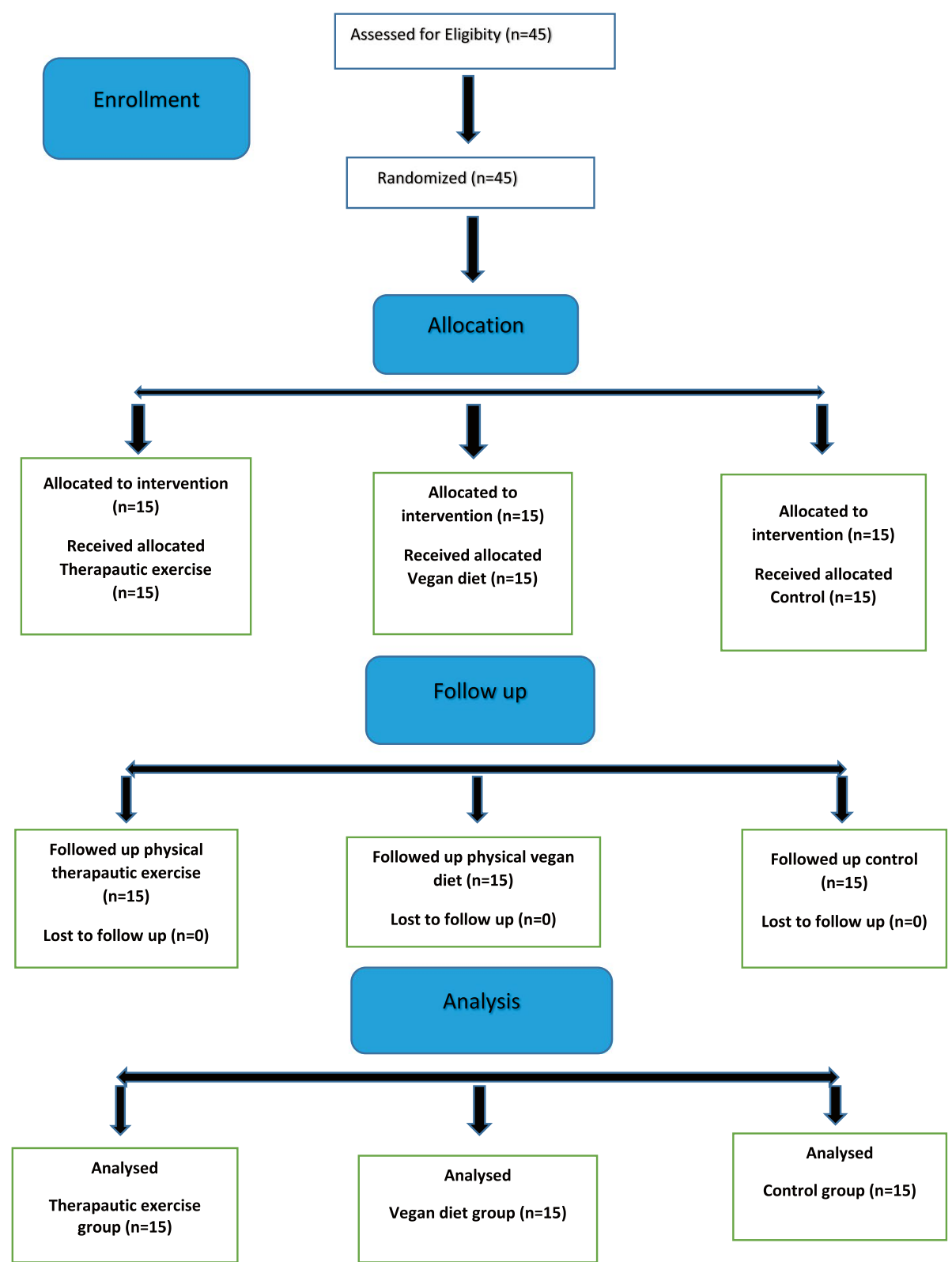

Fig. 1 The diagram describing the patient selection process and study flow

The study was conducted following the 'Ethical principles for medical research involving human subjects' of the Helsinki Declaration. Before commencement of the study, detailed information about the study and its relevance was given to each participant and informed consent was obtained from each participant.

\section{Intervention}

The body composition of participants was measured by a dietician with Tanita BC 545 N Inner Scan TM with bioelectrical impedance analysis. Before weighing, metal items were taken off by participants and stood barefooted on the scale. The bioimpedance scale had a capacity of $150 \mathrm{~kg}$, with a precision of $0.1 \mathrm{~kg}$ for weight and $0.1 \%$ for fat mass percentage, [29] with a criterion validity with dual-energy X-ray absorptiometry of $r=0.89$ [30]. Participants with chronic NSNP and vegan diet followed a diet programme prepared by a dietician under the supervision of an endocrinologist after body analysis. This diet programme includes grains, fruits, vegetables and legumes, as well as dairy products and eggs, known as a lacto-ovo vegetarian. Consumption of meat, poultry, 
fish, seafood and processed food and beverages was disallowed [31]. No calorie restriction was made in the diet, which was arranged according to the number of calories calculated by the expert dietician according to the body mass index (BMI). In the study, a lacto-ovo-vegetarian diet programme was preferred for participants to easily adapt to the study since a vegetarian diet was not previously followed. The diet programme lasted for 8 weeks. Participants in the DG used the My Fitness $\mathrm{Pal}^{\circledR}$ (MFP) mobile programme for diet tracking. MFP is a caloriecounting mobile app that allows users to track and input their daily food intake. MFP provides a breakdown of daily calorie and nutrient intake and gives feedback on the number of calories and nutrients needed [32]. In addition, participants shared their mobile programme information with the dietician daily and weekly for dietician control. Thus, the diet programme was controlled by a dietician.

Participants in the EG performed the following therapeutic exercises for 8 weeks, 3 days a week, accompanied by a physiotherapist [33].

1. The patient, sitting in the cervical spine neutral position, performs cervical spine flexion, extension and rotation, unloaded in the maximum possible range of motion ( 3 sets of 3 repetitions for each move).

2. The patient is in a supine position while the physiotherapist stabilises the shoulder (in the acromial region) with one hand and with the other making passive lateral glides, mobilising the nerve roots (bilaterally 3 times for $1 \mathrm{~min}$ ).

3. Patient in a supine position with the cervical spine in the neutral position will contract the cervical region deep muscles (flexors, extensors and rotators) without moving the spine (3 sets, 10-s repetitions for each muscle group).

4. In a supine position, the patient performs isometric neck flexion, lateral flexion and rotation against the manual resistance given by the physiotherapist (3 sets, 10-s repetitions for each muscle group).

5. The patient lying on her back does isometric neck extension against gravity (3 reps of $10 \mathrm{~s}$ ).

6. The patient performs isometric neck flexion, lateral flexion and rotation against the elastic band in the sitting position (3 sets of 10-s repetitions for each muscle group).

No intervention was made in the CG.

\section{Outcomes}

Bodyweight, fat percentage (FAT\%), BMI, (VAS) and Neck Disability Index (NDI) to evaluate the neck disability; Short Form-36 (SF-36) to evaluate the quality of life; and Tampa scale of Kinesiophobia (TSK) to evaluate the kinesiophobia were obtained before and after the study. VAS is a very common scale used for pain assessment in daily practice, and pain averages ranging from 0 to 10 are given in this assessment. Accordingly, ' 0 ' indicates no pain, 1-4 mild pain, 5-6 moderate pain and 7-10 severe pain [34]. NDI consists of a total of 10 titles as follows: intensity of pain, selfcare, lifting, reading, headache, concentration, working, driving, sleeping and resting activity. Each title was scored from 0 (no disability) to 5 (complete disability). The total score ranges from 0 (no disability) to 50 (total disability) [35]. SF-36 is a self-assessment scale consisting of 36 items, which measures eight dimensions: physical function (10 items), social function (2 items), role limitations due to physical problems (4 items), role limitations due to emotional problems (3 items), mental health (5 items), energy/vitality (4 items), pain ( 2 items) and general perception of health (5 items). Subscales evaluate health between 0 and 100. High scores from the test indicate well-being [36]. TSK is a 17 -item scale developed to measure the fear of movement/re-injury. The scale includes injury/re-injury and fear-avoidance parameters in work-related activities, with a 4-point Likert scoring. The total score ranges between 17 and 68. A high value on the TSK indicates a high degree of kinesiophobia [37].

\section{Statistical analysis}

Statistical Package for the Social Sciences 25 (IBM Corp. Released 2017. IBM SPSS Statistics for Windows, Version 25.0. Armonk, NY: IBM Corp.) package programme was used to evaluate the data. In the study, descriptive statistics (mean, standard deviation, median, first quartile, third quartile, number and percentile) were given for categorical and continuous variables. The homogeneity of variances, which is one of the prerequisites of the parametric tests, was checked with the Levene test. Normality assumption was checked with the Shapiro-Wilk test. The sphericity assumption was checked with the Mauchly test for repeated tests. The Sphericity Assumed test was applied with met sphericity assumption. The HuynhFeldt test was applied for cases where the epsilon value was $>0.75$ and the Greenhouse Geisser test for cases where it was smaller, with unmet sphericity assumption. Mixed order analysis of variance was used to make an overall assessment between repeated measures and patient groups, and Bonferroni-Dunn test was used for time effect. A $p$-value of $<0.05$ level was considered statistically significant. 
Table 1 The demographic data of participants

\begin{tabular}{|c|c|c|c|c|c|c|c|c|c|c|}
\hline & & \multirow[t]{2}{*}{ Diet } & \multirow[t]{2}{*}{ Exercise } & \multirow[t]{2}{*}{ Control } & \multicolumn{3}{|l|}{$T S^{a}$} & \multicolumn{3}{|l|}{$T S^{c}$} \\
\hline & & & & & $F$ & $p$ & $r$ & $F$ & $p$ & $r$ \\
\hline \multirow[t]{2}{*}{$\mathrm{BMI}\left(\mathrm{kg} / \mathrm{m}^{2}\right)$} & Pre & $\begin{array}{l}23.51 \pm 3.96 \\
23(20.2 ; 25.8)\end{array}$ & $\begin{array}{l}25.1 \pm 5.58 \\
23.4(20.9 ; 26.2)\end{array}$ & $\begin{array}{l}23.79 \pm 4.32 \\
21.6(20.4 ; 28.3)\end{array}$ & 1.612 & 0.212 & 0.071 & 1.218 & 0.306 & 0.055 \\
\hline & Post & $\begin{array}{l}22.61 \pm 3.23 \\
21.8(20.1 ; 24.9)\end{array}$ & $\begin{array}{l}26.59 \pm 9.3 \\
23.9(21 ; 29.9)\end{array}$ & $\begin{array}{l}23.65 \pm 4.15 \\
21.5(20.3 ; 28.3)\end{array}$ & 1.379 & 0.144 & 0.039 & & & \\
\hline$T S^{b}$ & & $\begin{array}{l}F=0.177 \\
p=0.676 \\
r=0.004\end{array}$ & $\begin{array}{l}F=2.7 \\
p=0.108 \\
r=0.06\end{array}$ & $\begin{array}{l}F=0.004 \\
p=0.948 \\
r=0.001\end{array}$ & & & & & & \\
\hline \multirow[t]{2}{*}{ FAT(\%) } & Pre & $\begin{array}{l}33.49 \pm 5.48 \\
32.9(29.3 ; 36.9)\end{array}$ & $\begin{array}{l}28.27 \pm 10.48 \\
31.5(22.3 ; 35.2)\end{array}$ & $\begin{array}{l}31.24 \pm 6.85 \\
28.9(25.5 ; 39.6)\end{array}$ & 1.656 & 0.203 & 0.073 & 0.302 & 0.741 & 0.014 \\
\hline & Post & $\begin{array}{l}33.07 \pm 4.56 \\
34(30.5 ; 35)\end{array}$ & $\begin{array}{l}29.09 \pm 7.27 \\
30.5(22.4 ; 34.5)\end{array}$ & $\begin{array}{l}31.27 \pm 6.73 \\
30(25.5 ; 39.2)\end{array}$ & 1.498 & 0.235 & 0.067 & & & \\
\hline$T S^{b}$ & & $F=0.136 p=0.714 r=0.003$ & $F=0.512 p=0.478 r=0.012$ & $F=0.001 p=0.982 r=0.001$ & & & & & & \\
\hline
\end{tabular}

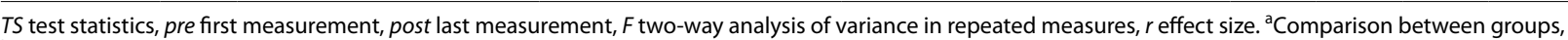
${ }^{b}$ intra-group comparison, 'comparison of pre and post values between groups, summary statistics mean \pm standard deviation; given as median (first quartile-third quartile) values

\section{Results}

\section{Age, BMI and body FAT\% of participants}

The demographic data of participants are presented in Table 1. The mean age of participants in DG was 21.6 \pm 1.64 years, $19.6 \pm 0.99$ years in EG and $21.53 \pm 2.03$ years in CG. Before and after treatment, the main effect of time on BMI and FAT\% was not significant in all groups $\left(p^{>} 0.05\right)$. No significant difference was found in the BMI and FAT\% before and after treatment in all groups $(p>0.05)$. The BMI and FAT\% were expressed in kilogramme/metre ${ }^{2}\left(\mathrm{~kg} / \mathrm{m}^{2}\right)$ and percentage $(\%)$, respectively.

Table 2 The neck disability, kinesiophobia and VAS scores of participants

\begin{tabular}{|c|c|c|c|c|c|c|c|c|c|c|}
\hline & & \multirow[t]{2}{*}{ Diet } & \multirow[t]{2}{*}{ Exercise } & \multirow[t]{2}{*}{ Control } & \multicolumn{3}{|l|}{$T S^{a}$} & \multicolumn{3}{|l|}{$T S^{c}$} \\
\hline & & & & & $F$ & $p$ & $r$ & $F$ & $p$ & $r$ \\
\hline \multirow[t]{2}{*}{ VAS (cm) } & Pre & $\begin{array}{l}6.07 \pm 1.16 \\
6(5 ; 7)\end{array}$ & $\begin{array}{l}6.4 \pm 1.06 \\
6(6 ; 7)\end{array}$ & $\begin{array}{l}6.8 \pm 0.94 \\
7(6 ; 8)\end{array}$ & 1.810 & 0.176 & 0.079 & 42.124 & 0.001 & 0.667 \\
\hline & Post & $\begin{array}{l}2.67 \pm 1.18 \\
2(2 ; 4)\end{array}$ & $\begin{array}{l}3.33 \pm 1.23 \\
3(3 ; 4)\end{array}$ & $\begin{array}{l}6.8 \pm 1.15 \\
7(6 ; 8)\end{array}$ & 52.524 & 0.001 & 0.714 & & & \\
\hline$T S^{b}$ & & $\begin{array}{l}F=138.632 \\
p=0.001 \\
r=0.767\end{array}$ & $\begin{array}{l}F=112.782 \\
p=0.001 \\
r=0.729\end{array}$ & $\begin{array}{l}F=0.001 \\
p=0.999 \\
r=0.001\end{array}$ & & & & & & \\
\hline \multirow[t]{2}{*}{ NSI } & Pre & $\begin{array}{l}35.47 \pm 10.13 \\
38(28 ; 42)\end{array}$ & $\begin{array}{l}35.87 \pm 12.29 \\
34(28 ; 50)\end{array}$ & $\begin{array}{l}37.07 \pm 7.67 \\
38(32 ; 42)\end{array}$ & 0.100 & 0.905 & 0.005 & 19.694 & 0.001 & 0.484 \\
\hline & Post & $\begin{array}{l}14.4 \pm 10.26 \\
14(8 ; 16)\end{array}$ & $\begin{array}{l}18.4 \pm 4.85 \\
18(16 ; 22)\end{array}$ & $\begin{array}{l}36.73 \pm 7.86 \\
38(35 ; 42)\end{array}$ & 33.485 & 0.001 & 0.615 & & & \\
\hline$T S^{b}$ & & $\begin{array}{l}F=71.217 \\
p=0.001 \\
r=0.629\end{array}$ & $\begin{array}{l}F=48.956 \\
p=0.001 \\
r=0.538\end{array}$ & $\begin{array}{l}F=0.018 \\
p=0.894 \\
r=0.001\end{array}$ & & & & & & \\
\hline \multirow[t]{2}{*}{ TSK } & Pre & $\begin{array}{l}41.8 \pm 5 \\
43(41 ; 45)\end{array}$ & $\begin{array}{l}40.73 \pm 5.13 \\
40(36 ; 44)\end{array}$ & $\begin{array}{l}42.93 \pm 3.03 \\
42(40 ; 46)\end{array}$ & 0.899 & 0.415 & 0.041 & 7.542 & 0.002 & 0.264 \\
\hline & Post & $\begin{array}{l}35.93 \pm 3.88 \\
36(32 ; 39)\end{array}$ & $\begin{array}{l}36.47 \pm 6.65 \\
35(32 ; 40)\end{array}$ & $\begin{array}{l}42.87 \pm 3.11 \\
42(41 ; 46)\end{array}$ & 9.704 & 0.001 & 0.316 & & & \\
\hline$T S^{b}$ & & $\begin{array}{l}F=28.926 \\
p=0.001 \\
r=0.408\end{array}$ & $\begin{array}{l}F=15.3 \\
p=0.001 \\
r=0.267\end{array}$ & $\begin{array}{l}F=0.004 \\
p=0.952 \\
r=0.001\end{array}$ & & & & & & \\
\hline
\end{tabular}

$T S$ test statistics, pre first measurement, post last measurement, $F$ two-way analysis of variance in repeated measures, $r$ effect size. ${ }^{a} C o m p a r i s o n$ between groups, ${ }^{b}$ intra-group comparison, ${ }^{C}$ comparison of pre and post values between groups, summary statistics mean \pm standard deviation; given as median (first quartile-third quartile) values 


\section{Neck disability and kinesiophobia scores of participants} The neck disability and kinesiophobia scores of participants are presented in Table 2. Before and after treatment, the main effect of time on the measurement was significant $[p=0.001$ (for neck disability); $p=0.002$ (for kinesiophobia)]. The between-group comparison revealed the post-treatment neck disability scores of the EG and DG as significantly different from the CG ( $p=$ $0.001)$. Intragroup value comparison before and after treatment revealed no significant difference in the CG $(p$ $=0.894)$, whereas a significant difference in the EG and DG $(p=0.001)$.

In group comparison, the post-treatment kinesiophobia scores of the EG and DG were significantly different from the CG $(p=0.001)$. The intragroup value comparison before and after treatment revealed no significant difference in the CG $(p=0.952)$, whereas a significant difference in the EG and DG $(p=0.001)$.

\section{VAS scores of participants}

The VAS scores of participants are presented in Table 2. Before and after treatment, the main effect of time on the measurement was significant $(p=0.001)$. The group comparison revealed that post-treatment VAS scores of the EG and DG were significantly different from the CG $(p=0.001)$. The intragroup value comparison before and after treatment revealed no significant difference in the CG $(p=0.999)$, whereas a significant difference in the EG and DG $(p=0.001)$. The VAS score was expressed in centimetres $(\mathrm{cm})$.

\section{SF-36 scores of participants}

The SF-36 scores of participants are presented in Table 3. Before and after treatment, the main effect of time on the measurement was significant. The between-group comparison revealed that post-treatment SF-36 scores of the EG and DG were significantly different from the CG. The post-treatment emotional role score was significantly different in the DG compared to the other two groups ( $p=$ 0.013). Post-treatment general health score was higher in the DG than in the EG $(p=0.001 ; p=0.013$, respectively). The intragroup value comparison before and after treatment revealed no significant difference in the CG, whereas a significant difference in the EG and DG (see Table 3).

\section{Discussion}

In our study, the effects of a vegan diet and therapeutic exercise for pain relief and quality of life and kinesiophobia improvement were investigated in patients with chronic NSNP. Results indicated that pain sensation decreased and the quality of life score increased in DG and EG. Furthermore, the kinesiophobia scores decreased in both groups. A vegan diet is an alternative option for chronic pain treatment.

The risk of chronic neck pain was higher in females than in males [38]. Several studies report that the incidence of chronic neck pain in females ranges from 7 to $22 \%$ compared with $5-16 \%$ in males $[39,40]$. Similarly, our study participants consisted of female patients. No significant difference was found in the body weight and body FAT\% before and after treatment in all groups since participants were of normal weight and the diet followed did not include calorie restriction. These results were similar to the study of Towery et al. [31].

Spinal manipulation, acupuncture, message, exercise, traction, electrotherapy and immobilisation with a soft collar are among the alternative treatment methods for neck pain. In a review, exercise was emphasised as the method with the highest evidence among the alternative treatment methods used in NSNP [41]. In another review, exercise was stated as the most effective and inexpensive method for NSNP management [42]. Considering the limited financial resources in the health system, decisionmakers should give great importance that applied treatments are effective and cheap [43]. Similarly, exercise and diet, which are cost-effective treatment methods, were applied to our study participants.

Studies revealed an impaired activity of the neck muscles in individuals with neck pain $[44,45]$. Cagnie et al. [46] reported that females with chronic neck pain had weaker neck extension strength than healthy females. Weakening of the deep cervical flexor and extensor muscles caused neck pain $[45,47]$. Decreased deep cervical muscle activity impaired joint movement and repetitive micro-trauma, resulting in neck pain. The best exercise prescription for neck muscles is a combination of resistance, endurance and stretching exercises [48]. Similarly, exercises applied in our study included resistance, endurance and stretching, and the pain scores of participants in the EG were significantly reduced.

Towery et al. [31] found that an 8-week vegan diet reduced the pain and improved the quality of life in individuals with chronic musculoskeletal pain. Similarly, our study revealed that pain scores of participants in the vegan DG decreased and their quality of life increased due to the positive effect of gut microbiota in the vegan diet. The gut microbiota consists of diverse microbial communities that compete with each other and produce metabolites that affect human health in many ways. Gut microbiota participates in the regulation of many neurological diseases, including Parkinson's disease, Alzheimer's disease, depression and chronic pain. Disruption of the gut microbiota causes neuroinflammation in the peripheral and central nervous systems $[49,50]$. Neuroinflammation is caused by cytokines and chemokines released from the glial cells. 
Table 3 SF-36 scores of participants

\begin{tabular}{|c|c|c|c|c|c|c|c|c|c|c|}
\hline & & \multirow[t]{2}{*}{ Diet } & \multirow[t]{2}{*}{ Exercise } & \multirow[t]{2}{*}{ Control } & \multicolumn{3}{|l|}{$T S^{a}$} & \multicolumn{3}{|l|}{$T S^{c}$} \\
\hline & & & & & $F$ & $p$ & $r$ & $F$ & $p$ & $r$ \\
\hline \multirow[t]{2}{*}{ Physical functioning } & Pre & $\begin{array}{l}67.67 \pm 12.8 \\
70(60 ; 80)\end{array}$ & $\begin{array}{l}71.27 \pm 17.23 \\
80(60 ; 85)\end{array}$ & $\begin{array}{l}60.33 \pm 10.6 \\
65(50 ; 70)\end{array}$ & 2.440 & 0.099 & 0.104 & 11.694 & 0.001 & 0.358 \\
\hline & Post & $\begin{array}{l}90 \pm 11.34 \\
90(75 ; 100)\end{array}$ & $\begin{array}{l}82 \pm 9.02 \\
80(75 ; 90)\end{array}$ & $\begin{array}{l}61 \pm 10.89 \\
60(50 ; 70)\end{array}$ & 30.724 & 0.001 & 0.594 & & & \\
\hline$T S^{b}$ & & $\begin{array}{l}F=49.614 \\
p=0.001 \\
r=0.542\end{array}$ & $\begin{array}{l}F=11.445 \\
p=0.002 \\
r=0.214\end{array}$ & $\begin{array}{l}F=0.044 \\
p=0.834 \\
r=0.001\end{array}$ & & & & & & \\
\hline \multirow[t]{2}{*}{ Role-physical } & Pre & $\begin{array}{l}26.67 \pm 27.49 \\
25(0 ; 50)\end{array}$ & $\begin{array}{l}26.33 \pm 25.18 \\
25(0 ; 50)\end{array}$ & $\begin{array}{l}36.67 \pm 22.89 \\
50(25 ; 50)\end{array}$ & 0.811 & 0.451 & 0.037 & 14.975 & 0.001 & 0.416 \\
\hline & Post & $\begin{array}{l}88.33 \pm 16 \\
100(75 ; 100)\end{array}$ & $\begin{array}{l}83.33 \pm 26.16 \\
100(75 ; 100)\end{array}$ & $\begin{array}{l}40 \pm 22.76 \\
50(25 ; 50)\end{array}$ & 21.800 & 0.001 & 0.509 & & & \\
\hline$T S^{b}$ & & $\begin{array}{l}F=54.194 \\
p=0.001 \\
r=0.563\end{array}$ & $\begin{array}{l}F=46.302 \\
p=0.001 \\
r=0.524\end{array}$ & $\begin{array}{l}F=0.158 \\
p=0.693 \\
r=0.004\end{array}$ & & & & & & \\
\hline \multirow[t]{2}{*}{ Role-emotional } & Pre & $\begin{array}{l}33.31 \pm 25.19 \\
33.3(33.3 ; 33.3)\end{array}$ & $\begin{array}{l}39.98 \pm 18.66 \\
33.3(33.3 ; 66.6)\end{array}$ & $\begin{array}{l}24.46 \pm 23.45 \\
33.3(0 ; 33.6)\end{array}$ & 1.779 & 0.181 & 0.078 & 2.388 & 0.010 & 0.102 \\
\hline & Post & $\begin{array}{l}57.72 \pm 15.24 \\
66.6(33.3 ; 66.6)\end{array}$ & $\begin{array}{l}48.86 \pm 27.79 \\
66.6(33.3 ; 66.6)\end{array}$ & $\begin{array}{l}31.08 \pm 26.6 \\
33.3(0 ; 66.6)\end{array}$ & 4.838 & 0.013 & 0.187 & & & \\
\hline$T S^{b}$ & & $\begin{array}{l}F=15.166 \\
p=0.001 \\
r=0.265\end{array}$ & $\begin{array}{l}F=2.007 \\
p=0.164 \\
r=0.046\end{array}$ & $\begin{array}{l}F=1.115 \\
p=0.297 \\
r=0.026\end{array}$ & & & & & & \\
\hline \multirow[t]{2}{*}{ Vitality } & Pre & $\begin{array}{l}35.33 \pm 12.46 \\
30(25 ; 45)\end{array}$ & $\begin{array}{l}44.33 \pm 14.13 \\
40(30 ; 60)\end{array}$ & $\begin{array}{l}35.33 \pm 12.32 \\
30(25 ; 45)\end{array}$ & 2.399 & 0.103 & 0.103 & 7.321 & 0.002 & 0.258 \\
\hline & Post & $\begin{array}{l}58.67 \pm 16.09 \\
60(50 ; 70)\end{array}$ & $\begin{array}{l}56.33 \pm 9.9 \\
50(50 ; 60)\end{array}$ & $\begin{array}{l}37 \pm 11.77 \\
40(25 ; 50)\end{array}$ & 12.846 & 0.001 & 0.380 & & & \\
\hline$T S^{b}$ & & $\begin{array}{l}F=33.938 \\
p=0.001 \\
r=0.447\end{array}$ & $\begin{array}{l}F=8.976 \\
p=0.005 \\
r=0.176\end{array}$ & $\begin{array}{l}F=0.173 \\
p=0.679 \\
r=0.004\end{array}$ & & & & & & \\
\hline \multirow[t]{2}{*}{ Mental Health } & Pre & $\begin{array}{l}48.27 \pm 18.05 \\
44(40 ; 60)\end{array}$ & $\begin{array}{l}52.2 \pm 18.01 \\
52(30 ; 68)\end{array}$ & $\begin{array}{l}42.13 \pm 16.36 \\
40(30 ; 56)\end{array}$ & 1.262 & 0.294 & 0.057 & 4.282 & 0.020 & 0.169 \\
\hline & Post & $\begin{array}{l}64.13 \pm 16.5 \\
68(52 ; 80)\end{array}$ & $\begin{array}{l}66.1 \pm 15.11 \\
64(56 ; 76)\end{array}$ & $\begin{array}{l}43.73 \pm 18.65 \\
40(30 ; 55)\end{array}$ & 8.136 & 0.001 & 0.279 & & & \\
\hline$T S^{b}$ & & $\begin{array}{l}F=18.03 \\
p=0.001 \\
r=0.3\end{array}$ & $\begin{array}{l}F=13.838 \\
p=0.001 \\
r=0.248\end{array}$ & $\begin{array}{l}F=0.183 \\
p=0.671 \\
r=0.004\end{array}$ & & & & & & \\
\hline \multirow[t]{2}{*}{ Social functioning } & Pre & $\begin{array}{l}50.83 \pm 20.85 \\
50(37.5 ; 62.5)\end{array}$ & $\begin{array}{l}56.67 \pm 18.22 \\
62.5(37.5 ; 75)\end{array}$ & $\begin{array}{l}50.83 \pm 16 \\
50(37.5 ; 62.5)\end{array}$ & 0.499 & 0.611 & 0.023 & 8.507 & 0.001 & 0.288 \\
\hline & Post & $\begin{array}{l}79.17 \pm 14.69 \\
75(62.5 ; 87.5)\end{array}$ & $\begin{array}{l}70 \pm 10.35 \\
75(62.5 ; 75)\end{array}$ & $\begin{array}{l}51.83 \pm 20.08 \\
50(37.5 ; 65)\end{array}$ & 11.995 & 0.001 & 0.364 & & & \\
\hline$T S^{b}$ & & $\begin{array}{l}F=36.446 \\
p=0.001 \\
r=0.465\end{array}$ & $\begin{array}{l}F=8.071 \\
p=0.007 \\
r=0.161\end{array}$ & $\begin{array}{l}F=0.045 \\
p=0.832 \\
r=0.001\end{array}$ & & & & & & \\
\hline \multirow[t]{2}{*}{ Body pain } & Pre & $\begin{array}{l}51.33 \pm 14.04 \\
57.5(35 ; 57.5)\end{array}$ & $\begin{array}{l}41.83 \pm 9.18 \\
45(35 ; 45)\end{array}$ & $\begin{array}{l}39.33 \pm 12.69 \\
35(32.5 ; 45)\end{array}$ & 4.075 & 0.024 & 0.163 & 29.975 & 0.001 & 0.588 \\
\hline & Post & $\begin{array}{l}81.83 \pm 10.63 \\
87.5(77.5 ; 90)\end{array}$ & $\begin{array}{l}71.5 \pm 14.26 \\
77.5(65 ; 77.5)\end{array}$ & $\begin{array}{l}40.5 \pm 11.35 \\
40(30 ; 45)\end{array}$ & 46.784 & 0.001 & 0.690 & & & \\
\hline$T S^{b}$ & & $\begin{array}{l}F=99.981 \\
p=0.001 \\
r=0.704\end{array}$ & $\begin{array}{l}F=94.593 \\
p=0.001 \\
r=0.693\end{array}$ & $\begin{array}{l}F=0.146 \\
p=0.704 \\
r=0.003\end{array}$ & & & & & & \\
\hline \multirow[t]{2}{*}{ General health } & Pre & $\begin{array}{l}46.67 \pm 17.18 \\
50(35 ; 60)\end{array}$ & $\begin{array}{l}44.33 \pm 14.98 \\
45(35 ; 50)\end{array}$ & $\begin{array}{l}40 \pm 11.02 \\
40(35 ; 45)\end{array}$ & 0.803 & 0.455 & 0.037 & 14.322 & 0.001 & 0.405 \\
\hline & Post & $\begin{array}{l}71 \pm 13.39 \\
75(60 ; 85)\end{array}$ & $\begin{array}{l}52.33 \pm 12.37 \\
50(50 ; 55)\end{array}$ & $\begin{array}{l}41.67 \pm 10.8 \\
40(35 ; 45)\end{array}$ & 22.091 & 0.001 & 0.513 & & & \\
\hline$T S^{b}$ & & $\begin{array}{l}F=61.999 \\
p=0.001 \\
r=0.596\end{array}$ & $\begin{array}{l}F=6.701 \\
p=0.013 \\
r=0.138\end{array}$ & $\begin{array}{l}F=0.291 \\
p=0.593 \\
r=0.007\end{array}$ & & & & & & \\
\hline
\end{tabular}

$T S$ test statistics, pre first measurement, post last measurement, $F$ two-way analysis of variance in repeated measures, $r$ effect size. ${ }^{a}$ Comparison between groups, ${ }^{b}$ intragroup comparison, 'comparison of pre and post values between groups, summary statistics mean \pm standard deviation; given as median (first quartile-third quartile) values 
Cytokines and chemokines are potent neuromodulators that induce hyperalgesia and allodynia. Increased cytokines and chemokines in the central nervous system cause chronic pain in many body regions through central sensitisation [51]. The omnivorous diet disrupts the gut microbiota and causes inflammation compared to the vegan diet [52]. In addition, studies revealed that anxiety and depression cause NSNP [53, 54]. Diet and lifestyle changes have positive effects on psychological diseases such as depression and anxiety [55]. Vegan individuals have lower anxiety levels than omnivore individuals [56]. Similarly, our study revealed a significantly different role-emotional score of SF-36 in the DG compared to the CG after treatment.

The general health score, one of the sub-dimensions of the SF-36 form, was higher in the DG compared to the EG. This result is not surprising. Numerous studies documented the positive effects of diet practices on general health. In addition, the exercise method applied was only for the neck muscles and excluded a general exercise prescription.

Our study revealed that kinesiophobia scores were significantly decreased in the DG and EG than CG due to neck pain relief in both groups. Patients with pain problems often fear that physical activity would worsen their conditions, which leads to movement and exercise avoidance [57]. Several studies showed that pain avoidance behaviour is closely related to pain chronicity and, consequently, loss of function $[58,59]$.

Our study has several limitations. The mood of participants was not evaluated with a separate scale before and after the study. The gut microbiota was also not examined. Therefore, mechanisms by which a vegan diet reduces pain were not fully determined.

\section{Conclusion}

We conclude that a vegan diet and therapeutic exercise have a beneficial effect on pain severity and quality of life in patients with chronic NSNP. Similar to the previous study, additional diet practices to physical therapy in painful musculoskeletal conditions yield positive results. Future large-scale studies can investigate the effects of a vegan diet on different musculoskeletal pains with different measurements and different durations.

\section{Acknowledgements}

Not applicable.

\section{Authors' contributions}

MST carried out the main idea of the study, writing the article, and final checks. GG and OT performed the patient selection and material method part of the study. MSN organised the diet programme and followed the patient. EA performed the statistical analysis. The authors read and approved the final manuscript.

\section{Funding}

No funds were used in the study.

\section{Availability of data and materials}

The datasets used and/or analysed during the current study are available from the corresponding author on reasonable request.

\section{Declarations}

Ethics approval and consent to participate

The study protocol was approved by the KTO Karatay University nonclinical research Ethics Committee (number: 41901325-050.99).

\section{Consent for publication}

Not applicable

\section{Competing interests}

The authors declare that they have no competing interests

\section{Author details}

${ }^{1}$ Department of Physical Therapy, Vocational School of Health Services, KTO Karatay University, Akabe Sq, Alaadin Kap St, 41, Karatay, Konya, Turkey. ${ }^{2}$ Department of Endocrinology and Metabolic Diseases, Konya Medicana Hospital, Selcuklu, Konya, Turkey. ${ }^{3}$ Department of Physical Therapy and Rehabilitation, Konya Farabi Hospital, Selcuklu, Konya, Turkey. ${ }^{4}$ Department of Diet, Konya Medicana Hospital, Selcuklu, Konya, Turkey. ${ }^{5}$ Faculty of Health Sciences, Department of Physical Therapy, İstanbul Okan University, Tuzla, İstanbul, Turkey.

Received: 13 October 2021 Accepted: 24 November 2021 Published online: 14 January 2022

\section{References}

1. Popescu A, Lee H. Neck pain and lower back pain. Med Clin North Am. 2020;104(2):279-92. https://doi.org/. https://doi.org/10.1016/j.mcna.2019. 11.003.

2. Hoy DG, Protani M, De R, Buchbinder R. The epidemiology of neck pain. Best Pract Res Clin Rheumatol. 2010;24(6):783-92.

3. Safiri S, Kolahi AA, Hoy D, Buchbinder R, Mansournia MA, Bettampadi D, et al. Global, regional, and national burden of neck pain in the general population, 1990-2017: systematic analysis of the Global Burden of Disease Study 2017. BMJ. 2020;26(368):m791.

4. Haines T, Gross AR, Burnie S, Goldsmith CH, Perry L, Graham N. A Cochrane review of patient education for neck pain. Spine J. 2009;9(10):859-71.

5. Monticone M, lovine R, de Sena G, Rovere G, Uliano D, Arioli G, et al. The Italian Society of Physical and Rehabilitation Medicine (SIMFER) recommendations for neck pain. G Ital Med Lav Ergon. 2013;35(1):36-50.

6. May S, Gardiner E, Young S, Klaber-Moffett J. Predictor variables for a positive long-term functional outcome in patients with acute and chronic neck and back pain treated with a McKenzie approach: a secondary analysis. J Man Manip Ther. 2008;16(3):155-60.

7. Hidalgo B, Hall T, Bossert J, Dugeny A, Cagnie B, Pitance L. The efficacy of manual therapy and exercise for treating non-specific neck pain: a systematic review. J Back Musculoskelet Rehabil. 2017;30(6):1149-69.

8. Barreto TW, Svec JH. Chronic neck pain: nonpharmacologic treatment. Am Fam Physician. 2019;100(3):180-2.

9. Fredin K, Lorås H. Manual therapy, exercise therapy or combined treatment in the management of adult neck pain - a systematic review and meta-analysis. Musculoskelet Sci Pract. 2017;31:62-71.

10. Haldeman S, Carroll L, Cassidy JD, Schubert J, Nygren A. The Bone and Joint Decade 2000-2010 Task Force on Neck Pain and Its Associated Disorders: executive summary. Spine (Phila Pa 1976). 2008;33(4):5-7.

11. Jull GA, Richardson CA. Motor control problems in patients with spinal pain: a new direction for therapeutic exercise. J Manip Physiol Ther. 2000;23(2):115-7

12. Gross A, Kay TM, Paquin JP, Blanchette S, Lalonde P, Christie T, et al. Exercises for mechanical neck disorders. Cochrane Database Syst Rev. 2015;28(1):CD004250.

13. Lévesque S, Pol JG, Ferrere G, Galluzzi L, Zitvogel L, Kroemer G. Trial watch: dietary interventions for cancer therapy. Oncoimmunology. 2019;8(7):1591878. 
14. Farooqui AA, Farooqui T. Effects of Western, Mediterranean, vegetarian, and Okinawan diet patterns on human brain. In: Farooqui T, Farooqui A editors. Role of the Mediterranean diet in the brain and neurodegenerative diseases: Elsevier Academic Press; 2018. p. 317-32.

15. Kalantar-Zadeh K, Fouque D. Nutritional management of chronic kidney disease. N Engl J Med. 2017;377(18):1765-76.

16. Appel $L$. The effects of dietary factors on blood pressure. Cardiol Clin. 2017;35(2):197-212.

17. Cramer H, Kessler CS, Sundberg T, Leach MJ, Schumann D, Adams J, et al. Characteristics of Americans choosing vegetarian and vegan diets for health reasons. J Nutr Educ Behav. 2017;49(7):561-567.e1.

18. Müller P. Vegan diet in young children. Nestle Nutr Inst Workshop Ser. 2020;93:103-10.

19. Wieseler-Frank J, Maier SF, Watkins LR. Central proinflammatory cytokines and pain enhancement. Neurosignals. 2005;14(4):166-74

20. Syauqy A, Hsu CY, Rau HH, Chao JC. Association of dietary patterns with components of metabolic syndrome and inflammation among middleaged and older adults with metabolic syndrome in Taiwan. Nutrients. 2018;10(2):143.

21. Mcphail K. C-reactive protein, chronic low back pain and, diet and lifestyle. Int Musculoskeletal Med. 2015;37(1):29-32.

22. Sutliffe JT, Wilson LD, de Heer HD, Foster RL, Carnot MJ. C-reactive protein response to a vegan lifestyle intervention. Complement Ther Med. 2015:23(1):32-7.

23. Sakkas H, Bozidis P, Touzios C, Kolios D, Athanasiou G, Athanasopoulou $E$, et al. Nutritional status and the influence of the vegan diet on the gut microbiota and human health. Medicina (Kaunas). 2020;56(2):88.

24. Huang RY, Huang CC, Hu FB, Chavarro JE. Vegetarian diets and weight reduction: a meta-analysis of randomized controlled trials. J Gen Intern Med. 2016;31(1):109-16.

25. Festa A, D'Agostino R Jr, Williams K, Karter AJ, Mayer-Davis EJ, Tracy RP, et al. The relation of body fat mass and distribution to markers of chronic inflammation. Int J Obes Relat Metab Disord. 2001;25(10):1407-15.

26. Glick-Bauer $M$, Yeh MC. The health advantage of a vegan diet: exploring the gut microbiota connection. Nutrients. 2014;6(11):4822-38.

27. Ren M, Lotfipour S. The role of the gut microbiome in opioid use. Behav Pharmacol. 2020;31(2\&3):113-21.

28. Torlak MS, Bagcaci S, Akpinar E, Okutan O, Nazli MS, Kuccukturk S. The effect of intermittent diet and/or physical therapy in patients with chronic low back pain: a single-blinded randomized controlled trial. Explore (NY). 2020;1550-8307(20):30284-6.

29. Vasold KL, Parks AC, Phelan DML, Pontifex MB, Pivarnik JM. Reliability and Validity of Commercially Available Low-Cost Bioelectrical Impedance Analysis. Int J Sport Nutr Exerc Metab. 2019;29(4):406-10.

30. Lintsi M, Kaarma H, Kull I. Comparison of hand-to-hand bioimpedance and anthropometry equations versus dual-energy $X$-ray absorptiometry for the assessment of body fat percentage in 17-18-year-old conscripts. Clin Physiol Funct Image. 2004;24(2):85-90.

31. Towery P, Guffey JS, Doerflein C, Stroup K, Saucedo S, Taylor J. Chronic musculoskeletal pain and function improve with a plant-based diet. Complement Ther Med. 2018:40:64-9.

32. Rebedew D. My Fitness Pal. Fam Pract Manag. 2015;22(2):31.

33. Martins-de-Sousa PH, Guimarães Almeida MQ da Silva Junior JM, Santos AS, Costa Araújo GG, de Oliveira PF, et al. Program of therapeutic exercises associated with electrotherapy in patients with chronic neck pain: Protocol for a randomized controlled trial. J Bodyw Mov Ther. 2020;24(1):25-30.

34. Boonstra AM, Schiphorst Preuper HR, Reneman MF, Posthumus JB, Stewart RE. Reliability and validity of the visual analogue scale for disability in patients with chronic musculoskeletal pain. Int J Rehabil Res. 2008;31(2):165-9.

35. Vernon H. The neck disability index: state of the art, 1991-2008. J Manip Physiol Ther. 2008;31(7):491-502.

36. Ware JE Jr, Sherbourne CD. The MOS 36-item short-form health survey (SF-36). I. Conceptual framework and item selection. Med Care. 1992;30(6):473-83.

37. Vlaeyen JWS, Kole-Snijders AMJ, Boeren RGB, van Eek H. Fear of movement/(re)injury in chronic low back pain and its relation to behavioral performance. Pain. 1995;62(3):363-72.

38. Goode AP, Freburger J, Carey T. Prevalence, practice patterns, and evidence for chronic neck pain. Arthritis Care Res. 2010;62(11):1594-601.
39. Ylinen J. Physical exercises and functional rehabilitation for the management of chronic neck pain. Eura Medicophys. 2007;43(1):119-32.

40. Webb R, Brammah T, Lunt M, Urwin M, Allison T, Symmons D. Prevalence and predictors of intense, chronic, and disabling neck and back pain in the UK general population. Spine (Phila Pa 1976). 2003;28(11):1195-202.

41. Cohen SP. Epidemiology, diagnosis, and treatment of neck pain. Mayo Clin Proc. 2015;90(2):284-99.

42. Miyamoto GC, Lin CC, Cabral CMN, van Dongen JM, van Tulder MW. Cost-effectiveness of exercise therapy in the treatment of non-specific neck pain and low back pain: a systematic review with meta-analysis. Br J Sports Med. 2019;53(3):172-81.

43. Robinson R. Economic evaluation and health care. What does it mean? BMJ. 1993;307:670-3

44. Barton PM, Hayes KC. Neck flexor muscle strength, efficiency, and relaxation times in normal subjects and subjects with unilateral neck pain and headache. Arch Phys Med Rehabil. 1996;77(7):680-7.

45. Falla D. Unravelling the complexity of muscle impairment in chronic neck pain. Man Ther. 2004;9(3):125-33.

46. Cagnie B, Cools A, De Loose V, Cambier D, Danneels L. Differences in isometric neck muscle strength between healthy controls and women with chronic neck pain: the use of a reliable measurement. Arch Phys Med Rehabil. 2007;88(11):1441-5.

47. Schomacher J, Farina D, Lindstroem R, Falla D. Chronic trauma-induced neck pain impairs the neural control of the deep semispinalis cervicis muscle. Clin Neurophysiol. 2012;123(7):1403-8.

48. O'Riordan C, Clifford A, Van De Ven P, Nelson J. Chronic neck pain and exercise interventions: frequency, intensity, time, and type principle. Arch Phys Med Rehabil. 2014;95(4):770-83.

49. Sharon G, Sampson TR, Geschwind DH, Mazmanian SK. The central nervous system and the gut microbiome. Cell. 2016;167(4):915-32.

50. Guo R, Chen LH, Xing C, Liu T. Pain regulation by gut microbiota: molecular mechanisms and therapeutic potential. Br J Anaesth. 2019;123(5):637-54

51. Ji RR, Nackley A, Huh Y, Terrando N, Maixner W. Neuroinflammation and central sensitization in chronic and widespread pain. Anesthesiology. 2018;129(2):343-66.

52. Franco-de-Moraes AC, de Almeida-Pititto B, da Rocha FG, Gomes EP, da Costa PA, Ferreira SRG. Worse inflammatory profile in omnivores than in vegetarians associates with the gut microbiota composition. Diabetol Metab Syndr. 2017;9:62.

53. Liu F, Fang T, Zhou F, Zhao M, Chen M, You J, et al. Association of depression/anxiety symptoms with neck pain: a systematic review and metaanalysis of literature in China. Pain Res Manag. 2018;2018:3259431.

54. Ortego G, Villafañe JH, Doménech-García V, Berjano P, Bertozzi L, Herrero $P$. Is there a relationship between psychological stress or anxiety and chronic nonspecific neck-arm pain in adults? A systematic review and meta-analysis. J Psychosom Res. 2016;90:70-81.

55. Null G, Pennesi L. Diet and lifestyle intervention on chronic moderate to severe depression and anxiety and other chronic conditions. Complement Ther Clin Pract. 2017;29:189-93.

56. Beezhold B, Radnitz C, Rinne A, DiMatteo J. Vegans report less stress and anxiety than omnivores. Nutr Neurosci. 2015;18(7):289-96.

57. Uluğ N, Yakut Y, Alemdaroğlu İ, Yılmaz Ö. Comparison of pain, kinesiophobia and quality of life in patients with low back and neck pain. J Phys Ther Sci. 2016;28(2):665-70.

58. Feleus A, van Dalen T, Bierma-Zeinstra SM, Bernsen RM, Verhaar JA, Koes BW, et al. Kinesiophobia in patients with non-traumatic arm, neck and shoulder complaints: a prospective cohort study in general practice. BMC Musculoskelet Disord. 2007;8:117.

59. Sarig Bahat $H$, Weiss PL, Sprecher E, Krasovsky A, Laufer Y. Do neck kinematics correlate with pain intensity, neck disability or with fear of motion? Man Ther. 2014;19(3):252-8.

\section{Publisher's Note}

Springer Nature remains neutral with regard to jurisdictional claims in published maps and institutional affiliations. 